\title{
Modeling and Robustness Study of Railway Transport Networks Using P-Timed Petri Nets
}

\author{
Anis Mhalla $\mathbb{D i D}^{1}$ and Mohanned Gaied ${ }^{2}$ \\ ${ }^{1}$ Research Laboratory LARA in Automatic Control, National Engineering School of Tunis (ENIT), \\ University of Tunis el Manar, Tunis, Tunisia \\ ${ }^{2}$ Research Unit LARATSI Automatic Signal and Image Processing, National Engineering School of Monastir,
} Avenue Ibn El Jazzar, 5019 Monastir, Tunisia

Correspondence should be addressed to Anis Mhalla; anis.mhalla@enim.rnu.tn

Received 1 May 2018; Revised 26 October 2018; Accepted 7 November 2018; Published 29 November 2018

Academic Editor: Silvio Simani

Copyright (C) 2018 Anis Mhalla and Mohanned Gaied. This is an open access article distributed under the Creative Commons Attribution License, which permits unrestricted use, distribution, and reproduction in any medium, provided the original work is properly cited.

\begin{abstract}
The importance of public transport systems continues to grow. These systems must respond to an increasing demand for population mobility and traffic disturbances. Rail transport networks can be considered as Discrete Event Systems (DES) with time constraints. The time factor is a critical parameter, since it includes dates to be respected in order to avoid overlaps, delays, and collisions between trains. P-time Petri Nets have been recognized as powerful modeling and analysis tools for railway transport systems. Temporal disturbances in these systems include railway infrastructure, traffic management, and disturbances (weather, obstacles on the tracks, malice, social movement, etc.). The developments presented in this paper are devoted to the modeling and the study of the robustness of the railway transport systems in order to evaluate the stability and the efficiency of these networks. In this study two robust control strategies towards time disturbances are presented. The first one consists of compensating the disturbance as soon as it is observed in order to avoid constraints violation. The second one allows generating, by the control, a temporal lag identical to the disturbance in order to avoid the death of marks on the levels of synchronization transitions of the P-time Petri net model.
\end{abstract}

\section{Introduction}

In railway transport systems, a temporal disturbance cannot be predicted or prevented. Our research focuses on the elimination and compensation of these disturbances by an application of robustness control techniques.

The robustness is defined as the ability of the system to preserve the specifications facing some expected or unexpected variations. The robustness is interpreted into different specializations. The passive robustness is based upon variations included in validity time intervals. There is no control loop modification to preserve the required specifications. On the other hand, active robustness uses observed time disturbances to modify the control loop in order to satisfy these specifications.

This paper deals with the modeling and the robust control facing disturbances of transportation systems. The system that motivated this study is a real railway transport network. In the system under consideration, the processing times are interval-valued. Otherwise, a processing time is selected between two bounds which depend on the operation to be performed. Any deviations (occurrence of a temporal disturbance) from the allowed lower (resp., upper) bounds will lead to a low service quality. Thus, the study of robustness of these systems is needed to be carried out.

The contributions of the present paper are

(i) The improvement of the time semantic of the railwauy network model with the introduction of the P-time PN model

(ii) Two robust control strategies towards time disturbances are presented. The first one consists of generating by the control a temporal shift similar to the disturbance, in order to avoid the death of marks 
on the levels of synchronization transitions of the P-time Petri net model. The second one rejects the disturbance as soon as it is observed, using the control. Some definitions are quoted in order to build a theory dealing with robustness problem. The main objective of the robust control strategy is to eliminate time perturbations on railway traffic

The reminder of this document is organized as follows. The first section begins the presentation of the studied railway transport system; the P-time Petri net is used as modeling tool. The second section is divided into two parts. The first presented some definitions concerning the robustness of DES with time constrains. The second one presents two approaches for robust control. These strategies aim to avoid the violation of time constraints in order to guarantee the stability and safety of railway traffic. Finally, the last section concludes the contributions and the originalities of this paper. Some interesting perspectives for further work are also proposed.

\section{Relevant Literature}

There has been much research considering the robustness of transportation systems in order to save time and to ameliorate service quality.

Khadilkar [1] proposes an evaluation of the robustness of a railway network with respect to operational delays. This work assumes that trains in the network operate on fixed routes and with reference to a timetable. A stochastic delay propagation model is proposed for identifying primary (externally imposed) delays and for computing the resultant secondary (knock-on) delays. The delay predictions are used to evaluate schedule robustness using two newly proposed metrics. Individual robustness measures the ability of trains to limit the adverse effects of their own primary delays. On the other hand, collective robustness measures the ability of the network as a whole, to limit the knock-on effects of primary delays imposed on a small fraction of trains.

Lusby et al. [2] survey the literature on robustness in railway planning problems, considering how robustness is conceptualized and modeled for the individual problems of railway. The main objective is to preserve the capacity for operations to continue at some level when faced with a disruption such as delay or failure

Network robustness is referred to as the capacity to absorb disturbances with a minimal impact on system performance. In this context, Cats et al. [3] propose reliability indicators that encompass changes in network performance with respect to the entire range of possible capacity reductions. Link criticality and degradation rapidity are measured by constructing network degradation curve that describe the relation between local capacity reduction and global change in network performance. The authors develop a public transport robustness assessment model which computes passenger flow distribution and network performance metrics under planned capacity reductions. The model is applied to the urban rail-bound network of Amsterdam.
Araret et al. [4] propose a novel method for robust estimation of railway vehicle velocity which uses only the angular velocity of the wheels. To this end, Linear Matrix Inequality (LMI) approach is used to synthesize a robust estimator established on a longitudinal vehicle model with dynamic friction properties. The developed estimator is tested for extreme scenarios.

Cats [5] proposed a method for evaluating the robustness value of alternative network designs. The method involves a full-scan of link failure disruption scenarios and assesses their implications on network integrity, passenger delays, and link criticality. The full-scan approach implies analyzing the impact of a disruption on each of the network links separately for each network alternative. The robustness value of a certain network alternative is then established by comparing networks in terms of their expected disruption impact.

$\mathrm{Qu}$ et al. [6] give an overview of real time traffic management of the railway network in case of disturbances. After briefly introducing the problem of disturbance management and basic mathematical formulations, a precise placement is made based on the effect of management decisions towards the various stakeholders. The application of these models in real life railway system is discussed based on the special constraints considered, the size of the railway network, and the calculation time. Most railway disturbance management models are tested in an experiment setting at present.

Other control approaches and applications can be found in Qu et al. [7], Zhao et al. [8], and Yap et al. [9].

\section{Case Study: Railway Transport Network}

3.1. Presentation of Railway Network. The railway network of the Sahel, Tunisia, was commissioned in 1984 between Sousse and Monastir, before being extended from Monastir to Mahdia. This line connects the main cities and agglomerations of the Sahel from Mahdia to Sousse, Figure 1. It ensures the transportation of passengers as well as goods. The Sahel train line is $70 \mathrm{Km}$ long and it is totally electrified.

The metros in the studied network make the ride several times a day in an average duration of $1 \mathrm{~h} 30 \mathrm{~min}$ (30 minutes from Sousse to Monastir and 1 hour from Monastir to Mahdia). Figure 1 presented the stations and the different trajectories durations between Mahdia and Sousse.

3.2. Modeling of Railway Transport Network. In transport networks field, modeling is a complex task that requires the development of appropriate models

(i) to ensure customer satisfaction

(ii) to propose a transport service taking into account functioning constraints such as respecting scheduling conditions and reducing waiting times

3.2.1. Modeling of the Rail Transport Networks. The objective of the modeling of transport networks is to obtain a usable representation and a perfect description in order to exploit it. Several tools and approaches for modeling transport networks have been proposed [7, 10, 11]. P-time Petri Nets are one of the most interesting tools. 


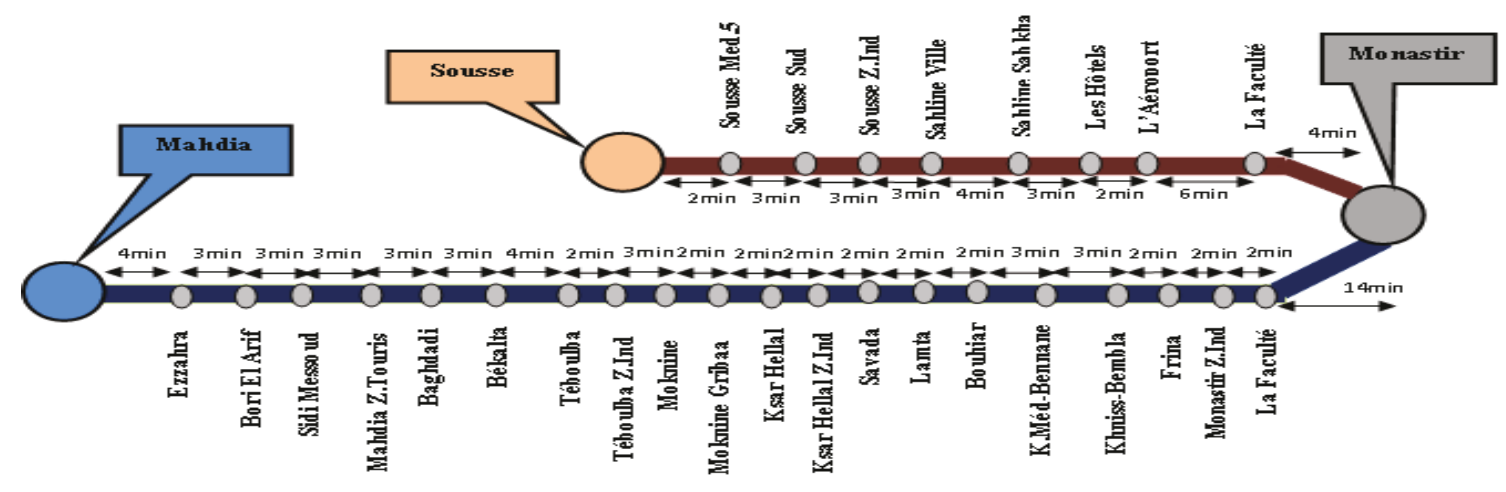

FIgURE 1: Sahel railway stations.

A/P-Time Petri Net. P-time Petri Nets (P-TPNs) are convenient tools for modeling the railway transport networks whose operations times are not precisely given but are included between a minimum and a maximum value.

Definition 1 (see [12]). The formal definition of a P-TPN is given by a pair $<\mathrm{R}$; I $>$ where

(i) $\mathrm{R}$ is a marked Petri net

(ii) $\mathrm{I}: \mathrm{P} \longrightarrow \mathrm{Q}^{+} \times\left(\mathrm{Q}^{+} \cup\{+\infty\}\right)$

$$
\mathrm{p}_{\mathrm{i}} \rightarrow \mathrm{IS}_{\mathrm{i}}=\left[\mathrm{a}_{\mathrm{i}}, \mathrm{b}_{\mathrm{i}}\right] \text { with } 0 \leq \mathrm{a}_{\mathrm{i}} \leq \mathrm{b}_{\mathrm{i}}
$$

$\mathrm{IS}_{\mathrm{i}}$ defines the static interval of staying time of a mark in the place $\mathrm{p}_{\mathrm{i}}$ belonging to the set of places $\mathrm{P}\left(\mathrm{Q}^{+}\right.$is the set of positive rational numbers). A mark in the place $p_{i}$ is taken into account in transition validation when it has stayed in $p_{i}$ at least a duration $\mathrm{a}_{\mathrm{i}}$ and no longer than $\mathrm{b}_{\mathrm{i}}$. After the duration $b_{i}$ the token will be dead.

B/Modeling. The Sahel railway network is composed of three terminals stations (Mahdia, Monastir, and Sousse) and twenty-eight stations.

\section{B-1/Parameters and Assumptions [13]}

(i) In the studied network, a time interval is associated with each operation $\left(\left[\mathrm{L}_{\mathrm{i}}, \mathrm{H}_{\mathrm{i}}\right]\right.$ with $u$.t: unit time). Its lower bound $\left(\mathrm{L}_{\mathrm{i}}\right)$ indicates the minimum time needed to execute the operation and the upper bound $\left(\mathrm{H}_{\mathrm{i}}\right)$ fixes the maximum time to not exceed.

(ii) A train can park in a principal station at least one minute. The static intervals associated with the three principal stations are ISp $\mathrm{IS}_{1}=\mathrm{ISp}_{45}=\mathrm{ISp}_{63}=[60,+\infty[$ (Figure 7).

(iii) The sojourn time of a metro in any other station is estimated from one to two minutes: $\operatorname{IS}_{i}=[60,120]$.

(iv) At the beginning of the traffic, it is assumed that four trains start from Mahdia station and two others are stationed at Sousse station.

Each train that arrives at the station will remain a waiting period before continuing its trajectory. This sojourn time is modeled by a temporal place $\mathrm{P}_{\mathrm{i}}$ (Figure 2 ).

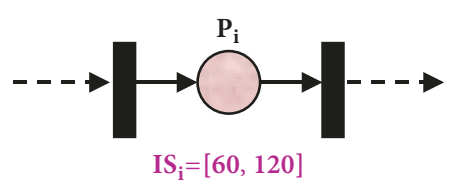

Figure 2: Station model.

Figure 3 shows a part of the P-time Petri Net modeling a single directional segment. On the graph

(i) red places represent the stations

(ii) white places represent the paths between two stations

Bidirectional segments exist between the stations of Bekalta and Mahdia touristic zone. On this path two crossover changes exist (Figure 4). The purpose of these crossovers is to allow at most one metro to exploit the railway road.

The P-TPN modeling the bidirectional segment case is represented by Figure 4 . The trajectory of the metro M1 (resp., M2) is modeled by the places $\mathrm{P}_{10}, \mathrm{P}_{12}, \mathrm{P}_{13}$, and $\mathrm{P}_{15}$ (resp. $\mathrm{P}_{15}$, $\mathrm{P}_{110}, \mathrm{P}_{12}, \mathrm{P}_{111}$, and $\mathrm{P}_{9}$ ). The places $\mathrm{P}_{11}$ and $\mathrm{P}_{14}$ represent two resources added to avoid the collision between the two metros M1and M2.

To ensure safety of the rail network, some monitoring places have been added (Figure 5). These places indicate the direction of circulation of the metro (green places $\mathrm{P}_{119}, \mathrm{P}_{120}$, $\mathrm{P}_{121}, \mathrm{P}_{122}, \mathrm{P}_{123}$, and $\left.\mathrm{P}_{124}\right)$.

Other places (places $\mathrm{P}_{134}$ and $\mathrm{P}_{138}$ ) (Figure 6) have been added to avoid the catching-up between two metros: if a metro "M1" parks at a station P6, the latter cannot be caught by a metro "M2", since the crossing of the transition T3 is conditioned by the presence of two tokens, respectively, at places P138 and P3.

3.2.2. Modeling of the Sahel Railway Network. Figure 7 shows the P-TPN model of the Sahel railway network. On this graph, the time associated with the places represents the durations of travel time between two successive stations. The evolution of the token represents the circulation of the trains on the railway. The track from Monastir to Sousse (resp. from Sousse 


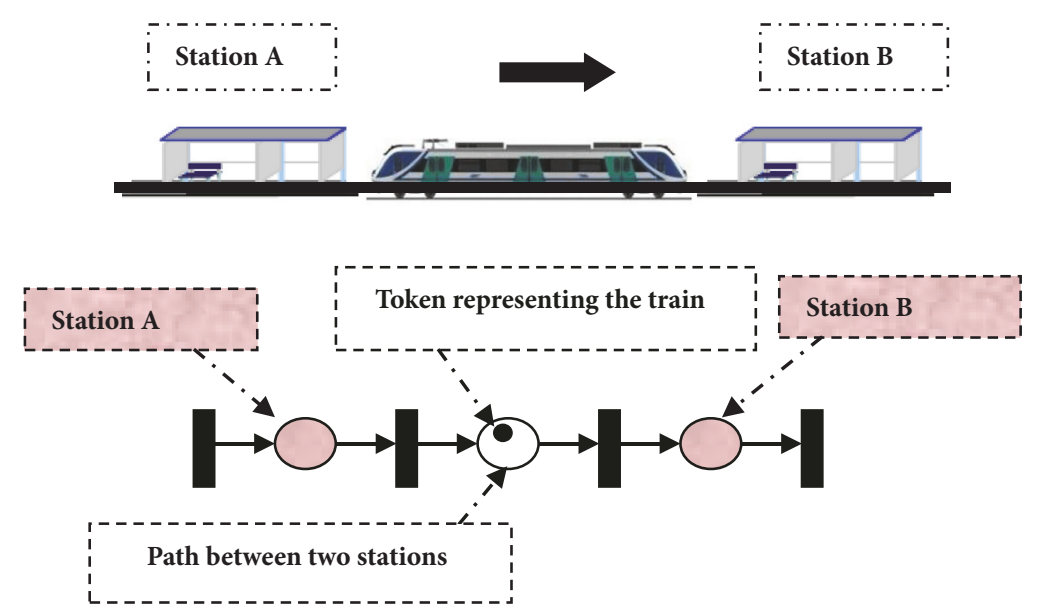

FIGURE 3: Single directional segment model.
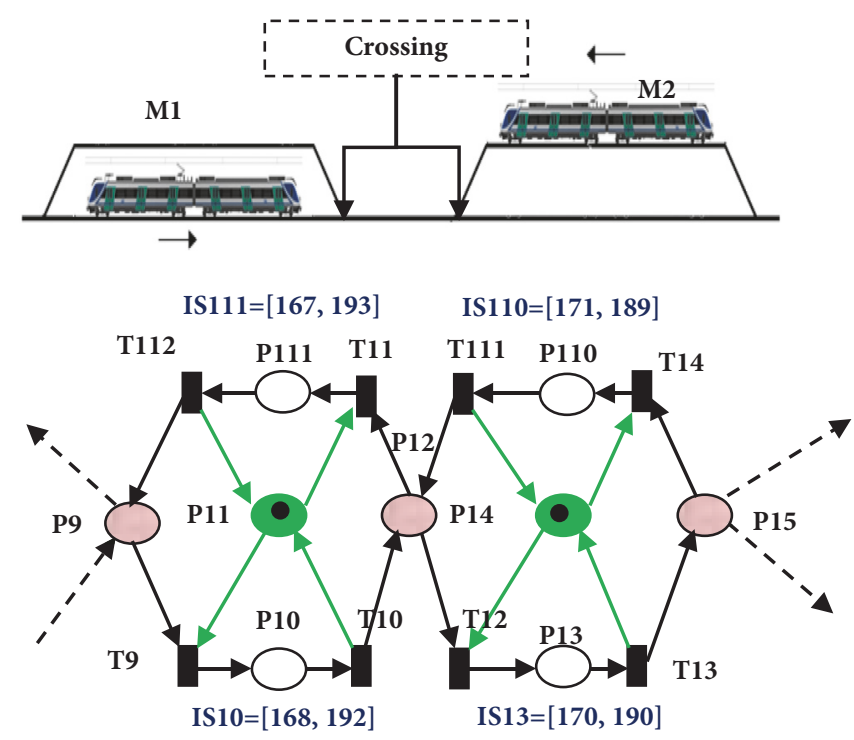

FIgURE 4: Bidirectional segment model.

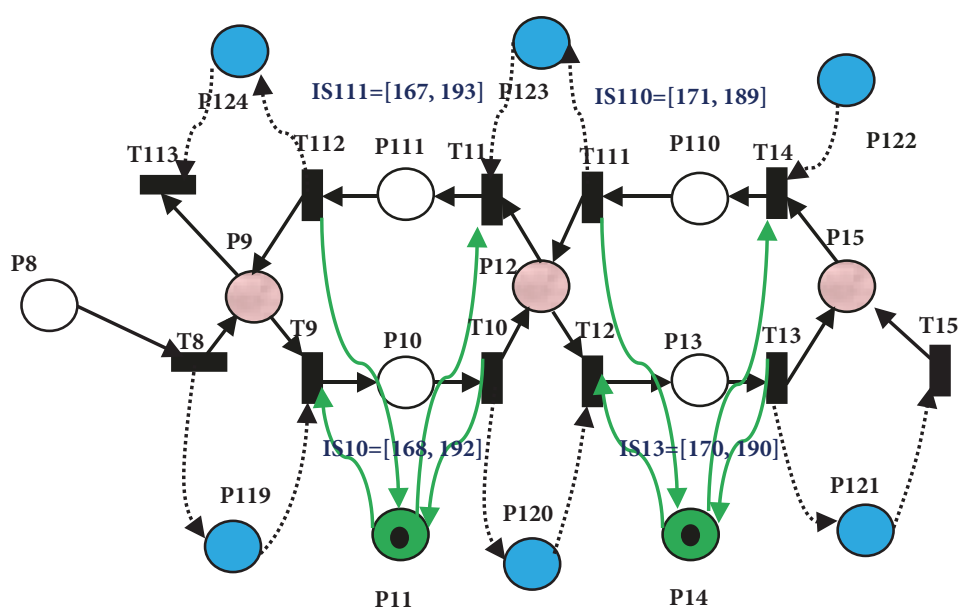

Figure 5: Places representing the direction of trains circulation. 


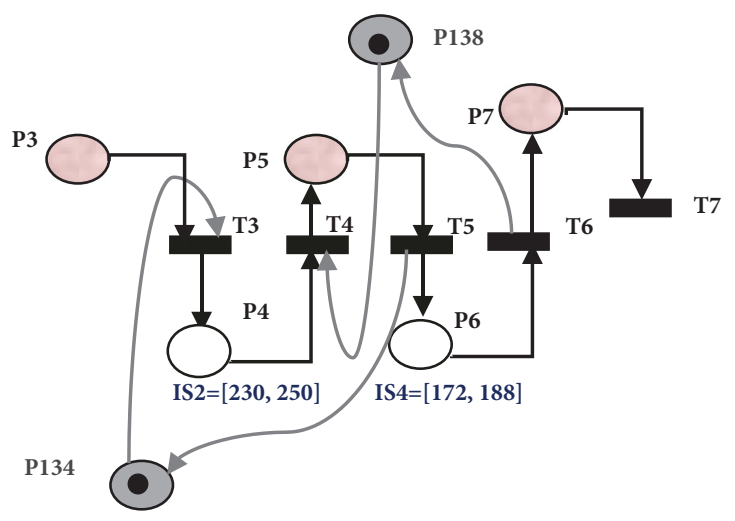

Figure 6: Catch-up places P133 and P137 [13].

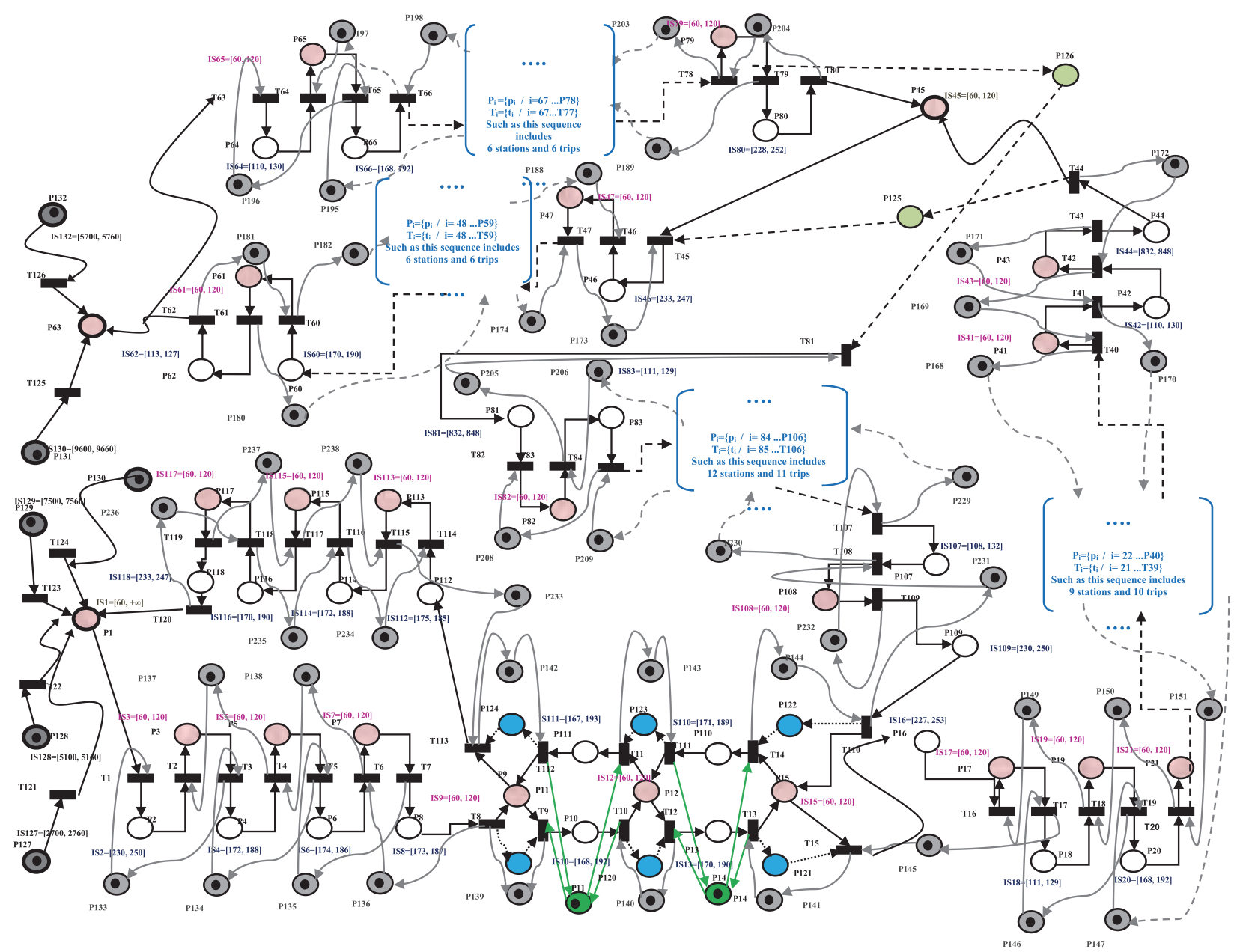

FIGURE 7: P-TPN model for the Sahel railway network [13].

to Monastir) is represented by the places $\mathrm{P}_{45}$ to $\mathrm{P}_{63}$ (resp., $\mathrm{P}_{63}$ to $\left.\mathrm{P}_{45}\right)$.

\section{Robustness Facing Time Disturbances \\ (i) Notations}

(i) $t_{i}{ }^{\circ}$ (resp., $\left.{ }^{\circ} t_{i}\right)$ : the output (resp., the input) places of the transition $t_{i}$ (ii) $\mathrm{p}_{\mathrm{i}}^{\circ}\left(\right.$ resp., $\left.{ }^{\circ} \mathrm{p}_{\mathrm{i}}\right)$ : the output transitions of the place $\mathrm{p}_{\mathrm{i}}$ (resp., the input transitions of the place $\mathrm{p}_{\mathrm{i}}$ )

(iii) $\mathrm{q}_{\mathrm{ie}}$ : the expected sojourn time of the token in the place $\mathrm{p}_{\mathrm{i}}$ (computed by scheduling layer)

(iv) $\mathrm{q}_{\mathrm{i}}$ : the effective sojourn time of the token in the place $p_{i}$

(v) $\mathrm{St}_{\mathrm{e}}(\mathrm{n}): \mathrm{n}^{\text {nd }}$ expected firing instant of the transition $\mathrm{t}$ 


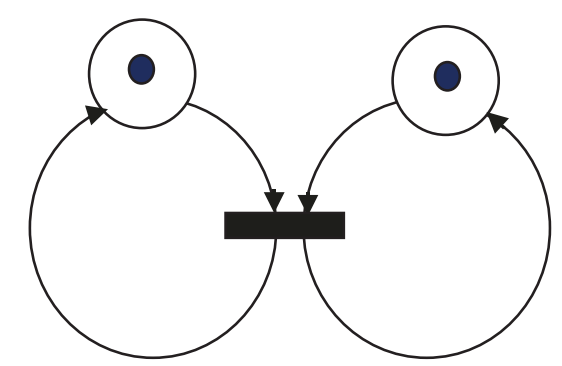

FIGURE 8: Structures leading to a death of a mark.

(vi) $\mathrm{IN}\left(\mathrm{p}_{\mathrm{th}}\right)$ : the first node of the path $\mathrm{p}_{\text {th }}$

(vii) $\operatorname{OUT}\left(\mathrm{p}_{\text {th }}\right)$ : the last node of the path $\mathrm{p}_{\text {th }}$

(viii) $\mathrm{T}_{\mathrm{C}}$ : the set of controllable transitions

(ix) $\mathrm{T}_{\mathrm{O}}$ : the set of observable transitions

(x) $T_{S}$ : the set of synchronization transitions

(xi) $\mathrm{St}_{\mathrm{e}}(\mathrm{n}): \mathrm{n}^{\text {nd }}$ expected firing instant of the transition $\mathrm{t}$ (computed by scheduling layer)

\subsection{Basic Definitions}

\section{Definition 2.}

(i) A transition is said to be observable if the occurrences of internal or external events of the system are observable on $\mathrm{t}_{\mathrm{O}}$ with $\mathrm{t}_{\mathrm{O}} \in \mathrm{T}_{\mathrm{O}}$. In this case the firing instant of the transition is known without any performed computation [14].

(Example: the detection of the end or the beginning of an operation with sensor)

(ii) A commandable transition "tc" corresponds to a controllable physically event [15]. These transitions are used for the temporal control which is defined as a modification of transitions firing instants.

(iii) The synchronization mechanism is the reason for the death of marks. This death, on the level of synchronization transition "ts", is caused if the marks belonging to the circuits do not arrive at compatible moments in their input places [12] (Figure 8).

Definition 3. A path $\left(\mathrm{p}_{\text {th }}\right)$ in a P-time $\mathrm{PN}$ is defined as an orderly and oriented succession of places $(\mathrm{p} \epsilon \mathrm{P})$ and $(\mathrm{t} \epsilon \mathrm{T})$, such as Succ $(t)=p$ and Succ $(p)=t(\operatorname{Succ}(K)$ denotes the successor of $K$ in the path $p_{\text {th }}$ ).

Definition 4 (see [16]). A monosynchronized subpath $\mathrm{Sp}_{\text {th }}$ is a path containing one and only one synchronization transition which is its last node. A perturbation $\Omega$ is locally rejected by a path " $\mathrm{p}_{\mathrm{th}}$ " if its last transition is fired as it is planned.

Definition 5. The robustness is defined as the aptitude of the system to preserve its specified properties against foreseen or unforeseen variations [17]. The robustness characterizes the global capacity to deal with disturbances.

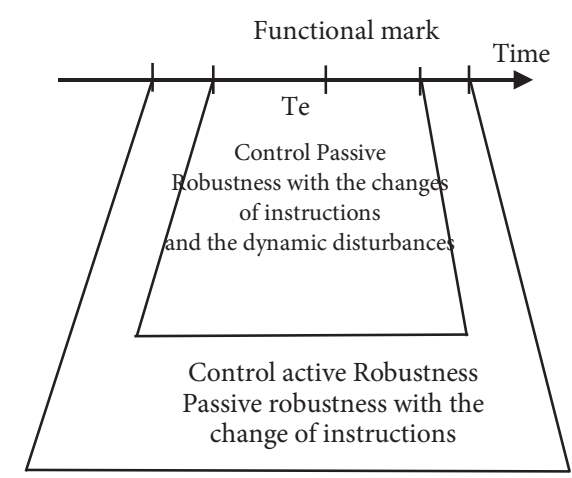

FIgURE 9: Active and passive robustness.

Definition 6. Active robustness corresponds if a change in control is necessary, so the properties specified by the schedule of conditions are not always preserved in the presence of perturbations [17].

Definition 7. An active robustness is a robustness ensured by the temporal control of the process transitions. Figure 9 shows the concepts of passive and active robustness developed in [17].

The passive robustness is based upon variations included in validity time intervals. There is no control to preserve the required specifications. In this case, two concepts are introduced compensable and transmissible margins. The compensable (respectively, the transmissible) margins noted $\Lambda \mathrm{c}($ resp., $\Lambda \mathrm{t})$ on subpath $\mathrm{k}\left(\mathrm{Sp}_{\text {thk }}\right)$ can be computed by using the following formulas:

$$
\Lambda_{\text {Spthk }}=\Lambda \mathrm{c}_{\text {Spthk }}+\Lambda \mathrm{t}_{\text {Spthk }}
$$

with

$$
\begin{aligned}
& \Lambda c_{\text {Spthk }}=\min _{\mathrm{p}_{\mathrm{i}} \in \mathrm{Sp}_{\text {thk }}}\left(\mathrm{q}_{\mathrm{ie}}-\mathrm{H}_{\mathrm{i}}\right), \\
& \Lambda \mathrm{c}_{\text {Spthk }}=\min _{\mathrm{p}_{\mathrm{i}} \in S_{\mathrm{p} \text { thk }}}\left(\mathrm{Hi}-\mathrm{q}_{\mathrm{ie}}\right)
\end{aligned}
$$

In our study the introduction of the compensable and transmissible margin on the monosynchronized subpath $\mathrm{Sp}_{\text {thk }}$ makes it possible to compensate accumulated delays and to preserve the quality and safety of the railway traffic by eliminating the perturbations which arise on the level of static intervals associated with places of the P-time PN model. Consequently passive robustness characterizes the ability of the system to maintain the qualities specified for outputs without any new specific action being implemented. In the studied railway network, the passive robustness keeps the operating frequency of the rail network since it will be possible to manage disturbances residue on the level of static intervals manifested by minor perturbations which does not influence the stability of the railway traffic. The overall goal is to avoid degraded service quality (traffic perturbation, cumulative delay, travelers claims, etc.) and preserve stability and the security of the railway networks. 
Definition 8 (see [17]). A temporal control is the modification of transitions firing instants using controlled P-time Petri net. The Controlled P-time Petri net is defined by a quadruplet $\mathrm{Rpc}=\left(\mathrm{Rp}, \varphi, \mathrm{U}, \mathrm{U}_{0}\right)$ such that

(i) Rp is a P-time Petri net which describes the opened loop system

(ii) $\varphi$ is an application from the set of places (P) towards the set of operations $(\Gamma): \varphi: \mathrm{P} \longrightarrow \Gamma$

(iii) $\mathrm{U}$ is the external control of the transitions ( $\mathrm{T}$ ) of $\mathrm{Rp}$ built on the predicates using the occurrence of internal or external observable events of the system: $\mathrm{U}: \mathrm{T} \longrightarrow\{0,1\}$

(iv) $\mathrm{U}_{0}$ is the initial value of the predicate vector

The controlled P-time Petri net is used for the temporal control which is defined as a modification of transitions firing instants.

4.2. Robustness Approach. In the case of active robustness (the temporal disturbances exceed the bounds of the intervals associated with the operations) two approaches are developed.

The first strategy consists of compensating the disturbance by generating a temporal shift on the level of controllable transitions belonging of the propagation path of the disturbance. The second strategy aims to generate by the control, on the parallel paths, a temporal shift similar to the disturbance in order to avoid the schedule conditions violation.

\subsubsection{First Approach: Compensation of the Disturbance}

A/Principle. In railway transport, the determining parameter for service quality is the time which must belong to a very strict validity interval. The control guarantees the respect of these specifications.

The developed control strategy consists of compensating the disturbance as soon as its observation in order to avoid constraints violation on the levels of synchronization transitions of P-time PN model.

If the disturbance is an advance (resp. delay), the proposed strategy allows yielding delay (resp., advance) on the level of controlled transitions firing, belonging of the propagation path of the disturbance. The overall goal is to preserve schedule conditions and to ensure the safety and stability of rail traffic

Definition 9. The passive rejection ability interval of a path " $\mathrm{p}_{\text {th }}$ " is $\operatorname{PR}\left(\mathrm{p}_{\mathrm{th}}\right)=\left[\operatorname{PRa}\left(\mathrm{p}_{\mathrm{th}}\right), \operatorname{PRd}\left(\mathrm{p}_{\text {th }}\right)\right]$ where

$$
\begin{aligned}
& \operatorname{PRa}\left(\mathrm{p}_{\text {th }}\right)=\sum_{\mathrm{p}_{\mathrm{i}} \in \mathrm{P}_{\text {th }}}\left(\mathrm{q}_{\mathrm{ie}}-\mathrm{H}_{\mathrm{i}}\right), \\
& \operatorname{PRd}\left(\mathrm{p}_{\text {th }}\right)=\sum_{\mathrm{p}_{\mathrm{i}} \in \mathrm{P}_{\text {th }}}\left(\mathrm{q}_{\text {ie }}-\mathrm{L}_{\mathrm{i}}\right) .
\end{aligned}
$$

$\operatorname{PRa}\left(\mathrm{p}_{\text {th }}\right)$ (resp., $\left.\operatorname{PRd}\left(\mathrm{p}_{\mathrm{th}}\right)\right)$ is called the time passive rejection ability for an advance (resp., a delay) time disturbance.
Definition 10 (see [18]). The available control margin for an advance, $\mathrm{CMa}\left(\mathrm{p}_{\mathrm{i}}\right)$, and the available control margin for a delay, $C M d\left(p_{i}\right)$, associated with the place $p_{i}$ are defined as

CMa: $\mathrm{P} \longrightarrow \mathrm{Q}^{-}$

$$
\mathrm{p}_{\mathrm{i}} \longrightarrow \mathrm{CMa}\left(\mathrm{p}_{\mathrm{i}}\right)= \begin{cases}\mathrm{L}_{\mathrm{i}}-\mathrm{q}_{\mathrm{ie}} & \text { if } \mathrm{q}_{\mathrm{i}} \leq \mathrm{L}_{\mathrm{i}} \\ \mathrm{q}_{\mathrm{i}}-\mathrm{q}_{\mathrm{ie}} & \text { if } \mathrm{L}_{\mathrm{i}}<\mathrm{q}_{\mathrm{i}}<\mathrm{q}_{\mathrm{ie}} \\ 0 & \text { if } \mathrm{q}_{\mathrm{ie}} \leq \mathrm{q}_{\mathrm{i}} \leq \mathrm{H}_{\mathrm{i}}\end{cases}
$$

CMd: $\mathrm{P} \longrightarrow \mathrm{Q}^{+} \cup\{+\infty\}$

$$
\mathrm{p}_{\mathrm{i}} \rightarrow \operatorname{CMd}\left(\mathrm{p}_{\mathrm{i}}\right)= \begin{cases}\mathrm{H}_{\mathrm{i}}-\mathrm{q}_{\mathrm{ie}} & \text { if } \mathrm{q}_{\mathrm{i}} \leq \mathrm{q}_{\mathrm{ie}} \\ \mathrm{H}_{\mathrm{i}}-\mathrm{q}_{\mathrm{i}} & \text { if } \mathrm{q}_{\mathrm{ie}}<\mathrm{q}_{\mathrm{i}}<\mathrm{H}_{\mathrm{i}}\end{cases}
$$

A controllable transition $\left(\mathrm{t} \in \mathrm{T}_{\mathrm{C}}\right.$ ) constitutes an elementary subpath locally controllable on $\left[\max _{\mathrm{p}^{\mathrm{o}}{ }_{\mathrm{i}}=\mathrm{t}}\left(\mathrm{CMa}\left(\mathrm{p}_{\mathrm{i}}\right)\right), \min _{\mathrm{p}_{\mathrm{i}}^{\mathrm{o}}=\mathrm{t}}\right.$ $\left.\left(\mathrm{CMd}\left(\mathrm{p}_{\mathrm{i}}\right)\right)\right]$

B/Algorithm. This is a recursive algorithm allowing applying the approach of disturbance compensation (Figure 10). The presented algorithm allows computing the available control margin for a delay CMd (resp., an advance CMa) in a node n. This margin will be injected on the propagation path of the disturbance in order to avoid the death of tokens on the levels of synchronization transitions.

The algorithm is now presented:

(i) Consider G the P-time Petri net model of the railway transport system and $\delta$ an advance time disturbance in $\mathrm{p}_{\mathrm{k}}\left(\mathrm{p}_{\mathrm{k}} \in \mathrm{p}_{\mathrm{th}}\right)$, observed in a transition $\mathrm{t}\left(\mathrm{t} \in \mathrm{T}_{\mathrm{O}}\right)$

(ii) Let $\mathrm{S}_{\mathrm{pk}}$ (respectively, $\mathrm{S}_{\mathrm{OUT}(\mathrm{pth})^{\circ}}$ ) be the set of monosynchronized subpaths containing the place $\mathrm{p}_{\mathrm{k}}$ $\left(\right.$ respectively, OUT $\left(\mathrm{p}_{\mathrm{th}}\right)^{\circ}$ ) \{

$\mathrm{D}=\left\{\delta \mathrm{r}, \mathrm{OUT}\left(\mathrm{p}_{\mathrm{th}}\right)\right\}$ (D is a doublet composed of the residue of the disturbance and the output node of the path $\mathrm{p}_{\text {th }}$ )

$\forall \mathrm{p}_{\mathrm{th}} \in \mathrm{S}_{\mathrm{pk}} \Longrightarrow \delta \mathrm{r}=\delta+\operatorname{PRd}\left(\mathrm{p}_{\mathrm{th}}\right)$

If

$\delta \mathrm{r}>\left(\mathrm{H}_{\mathrm{i}}-\mathrm{q}_{\mathrm{ie}}\right) /\left\{\mathrm{p}_{\mathrm{i}}^{\mathrm{o}} \in \mathrm{T}_{\mathrm{S}} \wedge \mathrm{p}_{\mathrm{i}} \notin \mathrm{p}_{\text {th }} \wedge \mathrm{p}_{\mathrm{i}}^{\mathrm{o}} \in \mathrm{p}_{\text {th }}\right\}$, there is a control problem on $\mathrm{p}^{\mathrm{o}}$ : application of the control strategy allowing to compensate the disturbance

Else

$\delta \mathrm{r}<\left(\mathrm{H}_{\mathrm{i}}-\mathrm{q}_{\mathrm{ie}}\right) /\left\{\mathrm{p}_{\mathrm{i}}^{\mathrm{o}} \in \mathrm{T}_{\mathrm{S}} \wedge \mathrm{p}_{\mathrm{i}} \notin \mathrm{p}_{\text {th }} \wedge \mathrm{p}_{\mathrm{i}}^{\mathrm{o}} \in \mathrm{p}_{\text {th }}\right\} ;$ we apply the same procedure for each element of $\mathrm{S}_{\mathrm{OUT}(\mathrm{pth})^{\circ}}$ 


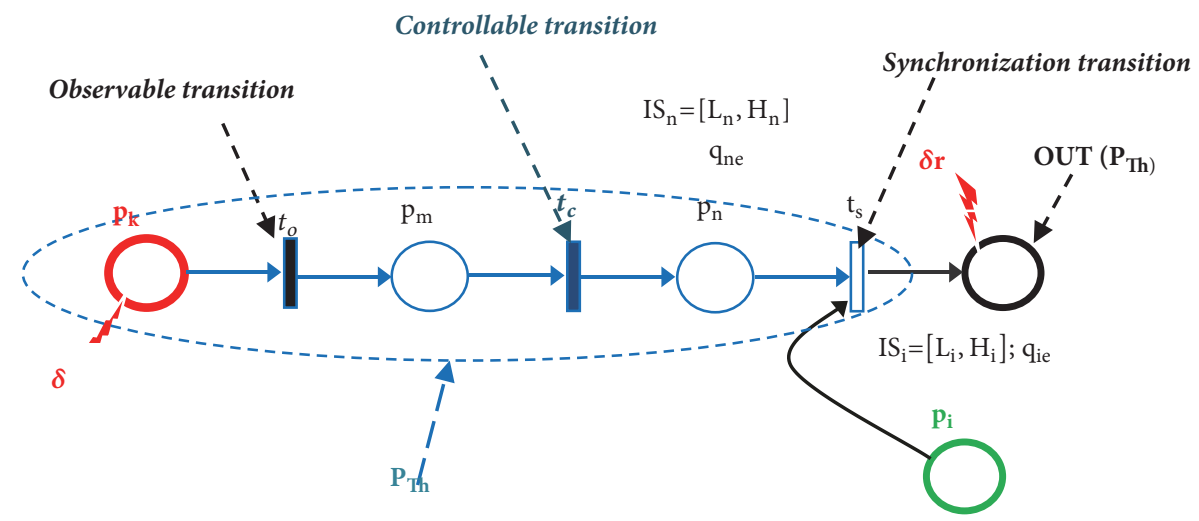

FIgURE 10: Example of disturbance propagation: Approach 1.

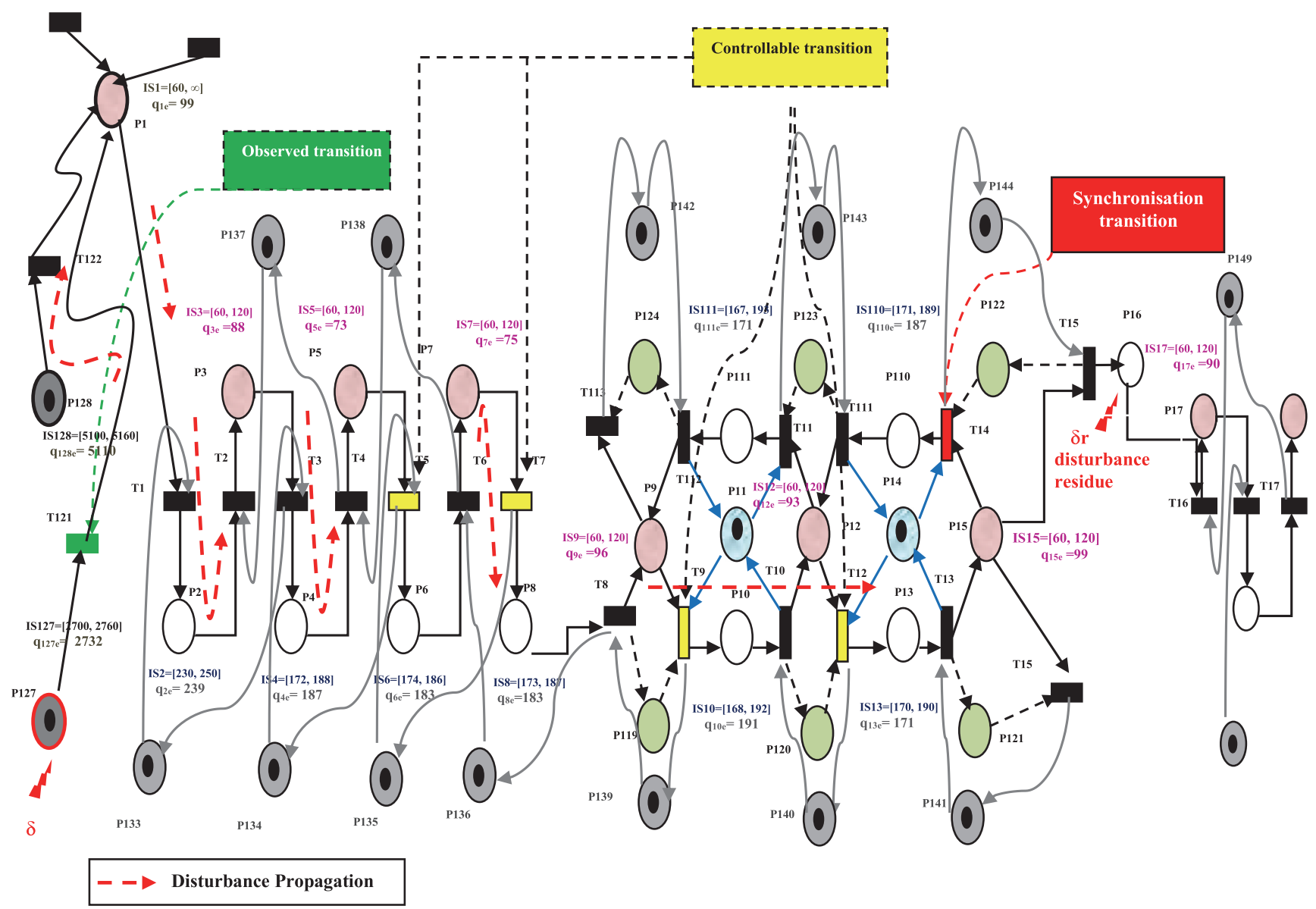

FIGURE 11: Example of disturbance propagation on railway network Mahdia-Monastir.

C/Application of the Robust Control Approach to the Railway Transport Network: Temporal Disturbance on the Railway (Mahdia-Monastir)

(i) Let $\delta=100$ a time disturbance in $\mathrm{p}_{127}$ (late departure of metro from Mahdia station ) observed in $t_{121}$. The disturbance $\delta$ is propagated towards the three subpaths $S p_{\text {th1 }}=\left(p_{127}, t_{121}, p_{1}, t_{1}\right), S p_{\text {th2 }}=\left(p_{2}, t_{2}\right.$, $\left.\mathrm{p}_{3}, \mathrm{t}_{3}, \mathrm{p}_{4}, \mathrm{t}_{4}, \mathrm{p}_{5}, \mathrm{t}_{5}\right)$, and $S \mathrm{p}_{\text {th3 }}=\left(\mathrm{p}_{6}, \mathrm{t}_{6}, \mathrm{p}_{7}, \mathrm{t}_{7}, \mathrm{p}_{8}, \mathrm{t}_{8}\right)$
(Figure 11). These three paths represent the trajectory of the metro, starting from the Mahdia station.

(ii) After the crossing of the transition $t_{8}$, the disturbance is propagated to the two paths $\mathrm{Sp}_{\mathrm{th} 4}=\left(\mathrm{p}_{9}, \mathrm{t}_{9}, \mathrm{p}_{10}, \mathrm{t}_{10}\right)$ and $S p_{\text {th } 5}=\left(p_{12}, t_{12}, p_{13}, t_{13}, p_{15}, t_{15}\right)$. On the path $\mathrm{Sp}_{\text {th5 }}$, the mark is available in $\mathrm{p}_{15}$ with a delay time equals to 100 u.t (unit time): there is a death of mark on the level of the synchronization transition $t_{14}\left(t_{14} \epsilon\right.$ 
TABLE 1: Available control margin for an advance and for a delay associated with place $\mathrm{p}_{\mathrm{i}}$.

\begin{tabular}{llr}
\hline Path & $\mathbf{C M a}\left(\mathbf{p}_{\mathbf{i}}\right)$ & $\mathbf{C M d}\left(\mathbf{p}_{\mathbf{i}}\right)$ \\
\hline $\mathrm{sp}_{\text {th2 }}=\left(\mathrm{p}_{2}, \mathrm{t}_{2}, \mathrm{p}_{3}, \mathrm{t}_{3}, \mathrm{p}_{4}, \mathrm{t}_{4}, \mathrm{p}_{5}, \mathrm{t}_{5}\right)$ & $\mathrm{CMa}\left(\mathrm{p}_{5}\right)=-13$ & $\mathrm{CMd}\left(\mathrm{p}_{5}\right)=47$ \\
$\mathrm{sp}_{\mathrm{th}}=\left(\mathrm{p}_{6}, \mathrm{t}_{6}, \mathrm{p}_{7}, \mathrm{t}_{7}, \mathrm{p}_{8}, \mathrm{t}_{8}\right)$ & $\mathrm{CMd}\left(\mathrm{p}_{7}\right)=45$ \\
$\mathrm{sp}_{\mathrm{th}}=\left(\mathrm{p}_{9}, \mathrm{t}_{9}, \mathrm{p}_{10}, \mathrm{t}_{10}\right)$ & $\mathrm{CMa}\left(\mathrm{p}_{7}\right)=-15$ & $\mathrm{CMd}\left(\mathrm{p}_{9}\right)=14$ \\
$\mathrm{sp}_{\mathrm{th5}}=\left(\mathrm{p}_{12}, \mathrm{t}_{12}, \mathrm{p}_{13}, \mathrm{t}_{13}, \mathrm{p}_{15}, \mathrm{t}_{15}\right)$ & $\mathrm{CMa}\left(\mathrm{p}_{9}\right)=-36$ & $\mathrm{CMd}\left(\mathrm{p}_{12}\right)=27$ \\
\hline
\end{tabular}

Ts) since there is no available control margin for a delay in $\mathrm{p}_{14}\left(\mathrm{CMd}\left(\mathrm{p}_{14}\right)=0\right)$.

(iii) Let us suppose that the transitions $t_{5}, t_{7}, t_{9}$, and $t_{12}$ are controllable. According to Definition 9, each transition belongs to a subpath locally controllable on $\left[\max _{\mathrm{p}_{\mathrm{i}}^{\mathrm{o}}=\mathrm{t}}\left(\mathrm{CMa}\left(\mathrm{p}_{\mathrm{i}}\right)\right), \min _{\mathrm{p}_{\mathrm{i}}^{\mathrm{o}}=\mathrm{t}}\left(\mathrm{CMd}\left(\mathrm{p}_{\mathrm{i}}\right)\right)\right]$.

(iv) Table 1 gives the available control margin for an advance $\mathrm{CMa}\left(\mathrm{p}_{\mathrm{i}}\right)$ and for a delay $\mathrm{CMd}\left(\mathrm{p}_{\mathrm{i}}\right)$, associated with each place $\mathrm{p}_{\mathrm{i}}$.

(v) An application of the proposed control strategy allows compensating this delay by injecting an advance on the firing instant of the controlled transitions of the propagation path of the disturbance. In fact since the transitions $t_{5}, t_{7}, t_{9}$, and $t_{12}$ are controllable, it is possible to generate an advances on the controlled transitions firing $\left(\mathrm{St}_{5}(\mathrm{n})=\mathrm{St}_{5 \mathrm{e}}(\mathrm{n})-13 ; \mathrm{St}_{7}(\mathrm{n})=\mathrm{St}_{7 \mathrm{e}}(\mathrm{n})-15\right.$; $\mathrm{St}(\mathrm{n})=\mathrm{St}_{9 \mathrm{e}}(\mathrm{n})-36$; and $\left.\mathrm{St}_{12}(\mathrm{n})=\mathrm{St}_{12 \mathrm{e}}(\mathrm{n})-33\right)$. As a result, the death of the mark in $p_{15}$ is then avoided and the residue $\delta \mathrm{r}=3$ is transmitted to the paths $\mathrm{Sp}_{\text {th }}=$ $\left(\mathrm{p}_{16}, \mathrm{t}_{16}, \mathrm{p}_{17}, \mathrm{t}_{17}\right)$ through the place $\mathrm{p}_{16}$. It is easily to check that the perturbation residue is totally rejected on the level of synchronization transition $t_{17}$ since the path $\mathrm{Sp}_{\text {th }}$ is locally controllable on $[-30,30]$.

(i) Physical Interpretation. In P-time PNs, if the upper limit is exceeded, there is a death of mark. The "death" of a token has to be seen as a time constraint violation. In the studied railway network, a death of token corresponds to illegal behavior. Thus, some disturbances can lead to a degraded service (traffic perturbation, cumulative delay, travelers claims, etc.) and influence the stability and the security of the networks.

In order to avoid the traffic delay (occurrence of time disturbance $\delta$ in $\mathrm{p}_{127}$ ), it is possible to catch up the late departure of the metro from Mahdia station by minimizing the staying time of the metro in the stations (generating an advances on the controlled transitions $t_{5}, t_{7}, t_{9}$, and $\left.t_{12}\right)$. This delay compensation makes it possible to avert catastrophic scenarios since it allows avoiding the collision with the metro arriving from the station of Bekalta (single railway lane shared between the two metros).

\subsubsection{Approach 2: Generation of a Time Shift Similar to the Disturbance}

A/Principle. On the parallel path of the propagation of the disturbance, this strategy allows generating, by the control, a temporal lag identical to the disturbance in order to avoid the constraints violation on the levels of synchronization transitions.
If the disturbance is an advance (respectively delay), the temporal lag will be an advance (respectively, a delay advance) generated by modifying the firing instants of controlled transitions belonging to the parallel path.

(i)

Lemma 11.

(i) Let us consider $\mathrm{Sp}_{\text {thK }}$ and $\mathrm{Sp}_{\text {thK }}$ two monosynchronized subpaths such that

$$
\operatorname{OUT}\left(\mathrm{Sp}_{\text {thK }}\right)=\operatorname{OUT}\left(\mathrm{Sp}_{\text {thL }}\right)=\text { ts. }
$$

(ii) Let $\Omega$ a time disturbance occurred in $I N\left(\mathrm{Sp}_{\mathrm{thK}}\right)$.

(iii) Let $\mathrm{P}_{\text {thL }}$ be $\mathrm{L}^{\text {nd }}$ path whose

$I N\left(\mathrm{P}_{\text {thL }}\right)=\mathrm{p}_{\mathrm{L}}$ : place containing a mark synchronized in a node $m$ with the disturbed token belonging to $\mathrm{P}_{\text {thK }}$.

If the disturbance is observed at the moment $t$ and there is at least a transition $t \in\left(\mathrm{T}_{\mathrm{C}} \cap \mathrm{P}_{\mathrm{thL}}\right)$ and $\Omega>\left(\mathrm{H}_{\mathrm{L}}-\mathrm{q}_{\mathrm{Le}}\right)$, then the approach of generation of a time shift similar to the disturbance can be applied on the parallel paths.

Proof. Let us take the example of Figure 12 .

Let $\Omega_{\mathrm{r}}$ the residue of the disturbance $\Omega\left(\Omega_{\mathrm{r}}=\Omega\right.$ $\left.\operatorname{PRd}\left(\operatorname{Lp}_{\mathrm{K}}\right)\right)$.

If $\Omega>\left(\mathrm{L}_{\mathrm{L}}-\mathrm{q}_{\mathrm{Le}}\right) /\left\{\left(\mathrm{p}_{\mathrm{L}}^{\mathrm{o}} \in \mathrm{T}_{\mathrm{S}}\right) \wedge\left(\mathrm{p}_{\mathrm{L}} \notin \mathrm{P}_{\mathrm{thK}}\right) \wedge\left(\mathrm{p}_{\mathrm{L}}^{\mathrm{o}} \in\right.\right.$ $\left.\left.\mathrm{P}_{\text {thK }}\right)\right\}$, there is a control problem on $\mathrm{p}_{\mathrm{L}}^{\mathrm{o}}$.

If there is no commandable transition $\left(t \in \mathrm{T}_{\mathrm{C}}\right)$ on the parallel path $\left(\mathrm{Lp}_{\mathrm{L}}\right)$, the approach of generation of a time shift similar to the disturbance cannot be applied.

B/Application of the Robust Control Approach: Temporal Disturbance on the Railway (Sousse-Monastir). Let $\Omega=80$ be a time disturbance in $\mathrm{p}_{77}$ observed in $\mathrm{t}_{77}$ (Figure 13).

(i) The disturbance $\Omega$ is transmitted to the two paths $\mathrm{Sp}_{\text {th } 7}=\left(\mathrm{p}_{77}, \mathrm{t}_{77}, \mathrm{p}_{78}, \mathrm{t}_{78}\right)$ and $\mathrm{sp}_{\text {th } 8}=\left(\mathrm{p}_{79}, \mathrm{t}_{79}, \mathrm{p}_{80}, \mathrm{t}_{80}\right.$, $\left.\mathrm{p}_{45}, \mathrm{t}_{45}\right)$ through the place $\mathrm{p}_{79}\left(\mathrm{Lp}_{\mathrm{K}}=\mathrm{Sp}_{\mathrm{th}} \cup \mathrm{Sp}_{\mathrm{th}}\right)$.

(ii) When the disturbance is observed in $\mathrm{t}_{45}$, a token stays in the place $\mathrm{p}_{125}$. This token belongs to the parallel path $\mathrm{Lp}_{\mathrm{L}}=\left(\mathrm{p}_{42}, \mathrm{t}_{42}, \mathrm{p}_{43}, \mathrm{t}_{43}, \mathrm{p}_{44}, \mathrm{t}_{44}, \mathrm{p}_{125}, \mathrm{t}_{45}\right)$. It is synchronized in $t_{45}$ with the disturbed token in $\mathrm{p}_{45}$. Since the available control margin for a delay associated with the place $\mathrm{p}_{125}$ is zero, there is a death of mark on the level of synchronization transition $t_{45}$. The application of the proposed control strategy allows the avoidance of the death of mark on transition $\mathrm{t}_{45}\left(\mathrm{t}_{45} \in \mathrm{Ts}\right)$ : indeed, since the two transitions $t_{43}$ and $t_{44}$ constitute two elementary subpaths locally 


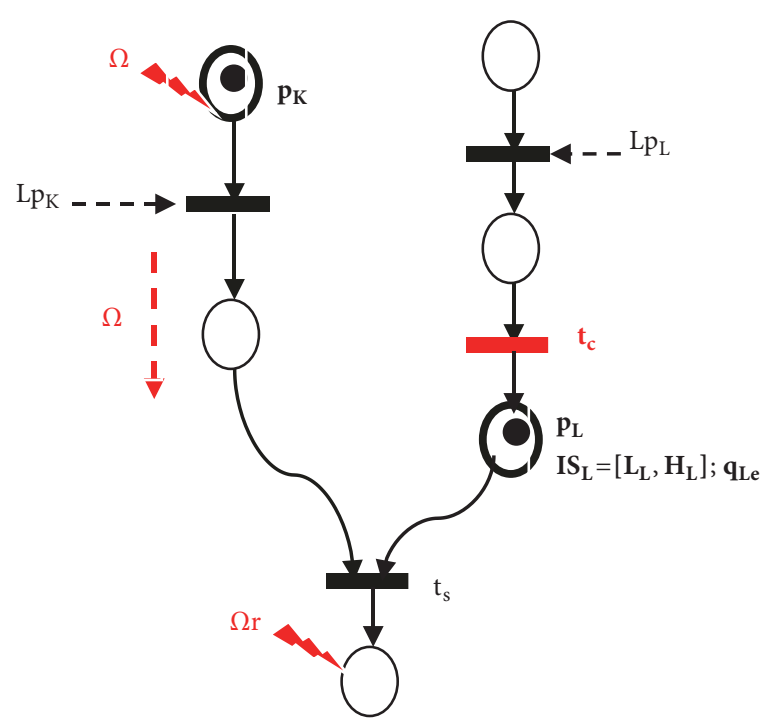

Figure 12: Propagation of disturbance on two parallel paths.

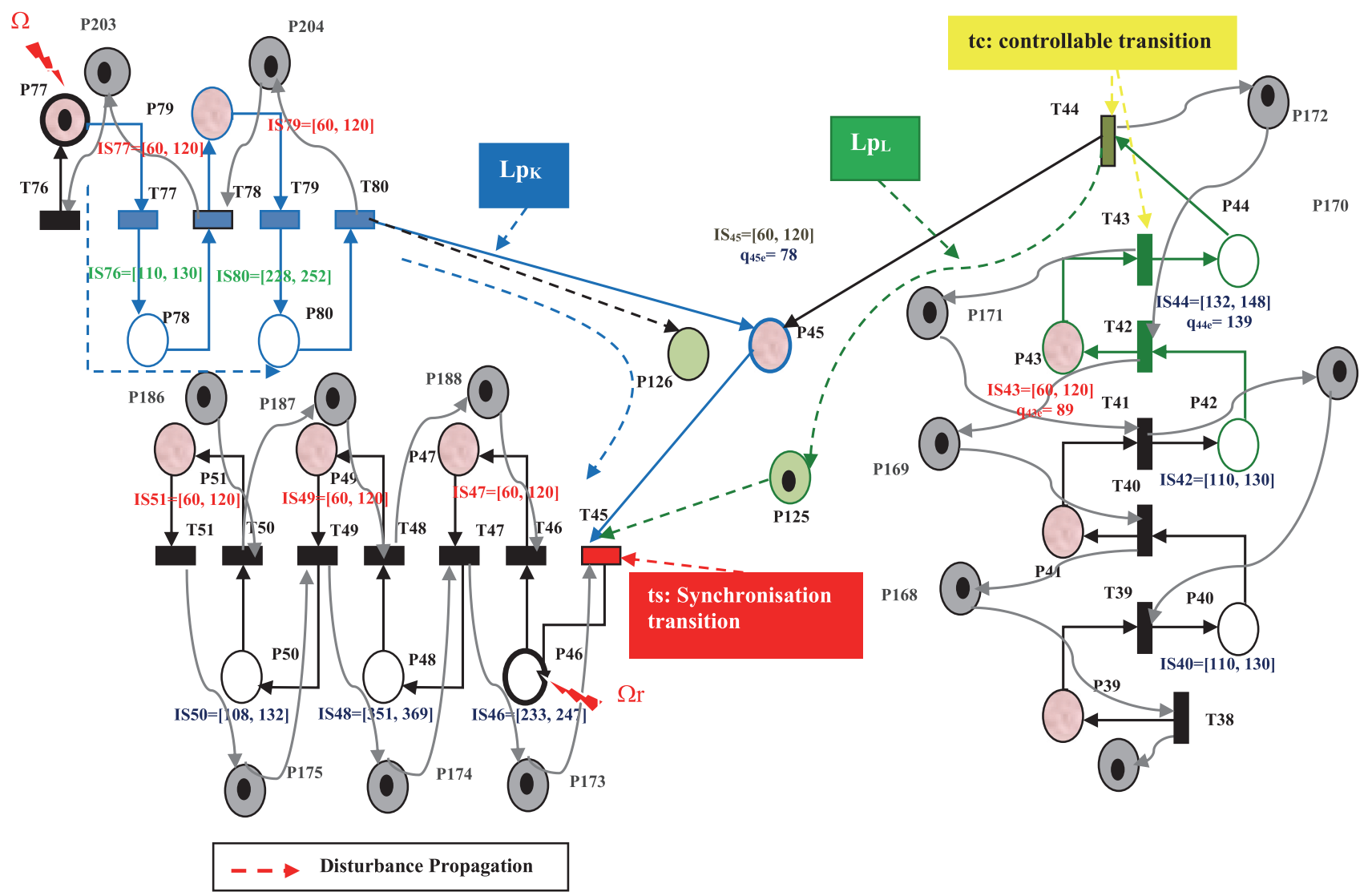

FIGURE 13: Example of disturbance propagation on the path (Sousse-Monastir).

controllable, respectively, on the intervals $[-29,31]$ and $[-7,9]$, we can inject by the control a delay on the firing instant of the transition $\mathrm{t}_{43}\left(\mathrm{St}_{43}(\mathrm{n})=\mathrm{St}_{43}(\mathrm{n})+33\right)$ and $\mathrm{t}_{44}\left(\mathrm{St}_{44}(\mathrm{n})=\mathrm{St}_{44}(\mathrm{n})+9\right)$. So, by generating delays on the controlled transitions firing, belonging to the parallel path $\left(\mathrm{Lp}_{\mathrm{L}}\right)$ of the propagation of the disturbance, the transition $t_{45}$ is fired normally (since $\left(\mathrm{CM}_{\mathrm{d}}\left(\mathrm{p}_{45}\right)=42\right)$ ), and the unavailability of marks on the levels of synchronization transitions is avoided. 
(ii) Physical Interpretation. The main objective of the proposed approach is to avoid disturbances in railway traffic. Indeed a temporal disturbance in our P-time PN model corresponds to a delay of a metro M1 at the station "aeroport" (place $\mathrm{P}_{77} \in \mathrm{Lp}_{\mathrm{L}}$ ). The noncompensation of the delay can lead to a collision between the metro M1 and the metro M2 arriving from Mahdia (path $\mathrm{Lp}_{\mathrm{L}}$ ). The idea is to delay the arrival of metro M2 (deceleration, delay on parking at the stations represented by the places $\mathrm{p}_{41}$ and $\mathrm{p}_{43}$ ) to the station of Monastir. This delay corresponds in our network to a temporal lag (modifying the firing instants of controlled transitions) allowing the avoidance of disturbance on railway traffic.

\section{Conclusion}

The modeling and the study of the robust control strategy facing disturbances in railway transport system constitute the main contributions of this paper. P-time Petri nets are used for modeling. Some definitions are quoted in order to build a theory dealing with robustness problem.

Two approaches for the robust control are presented. The first one consists of compensating the disturbance as soon as it is observed in order to avoid constraints violation on the levels of synchronization transitions of P-time PN model. The second strategy allows generating by the control, a temporal lag identical to the disturbance, on the parallel path of the propagation of the disturbance. It is shown that the established strategy allows averting catastrophic scenarios and avoiding the violation of time constraints in order to guarantee the stability and safety of railway traffic.

In the future, a comparative study based on several cases should be developed. A comparison between the approaches and results with the works of the diode theory [19] or the interval theory $[20,21]$ should also be considered.

It would be interesting to apply the proposed robustness approach to other problems, such as seaport terminal in order to avoid the low service quality and to minimize the overall production cost.

\section{Data Availability}

The data used to support the findings of this study are included within the article.

\section{Conflicts of Interest}

The authors declare that there are no conflicts of interest regarding the publication of this paper.

\section{References}

[1] H. Khadilkar, "Data-enabled stochastic modeling for evaluating schedule robustness of railway networks," Transportation Science, vol. 51, no. 4, pp. 1161-1176, 2017.

[2] R. M. Lusby, J. Larsen, and S. Bull, "A survey on robustness in railway planning," European Journal of Operational Research, vol. 266, no. 1, pp. 1-15, 2018.
[3] O. Cats, G.-J. Koppenol, and M. Warnier, "Robustness assessment of link capacity reduction for complex networks: Application for public transport systems," Reliability Engineering \& System Safety, vol. 167, pp. 544-553, 2017.

[4] Ö. Ararat and M. T. Söylemez, "Robust velocity estimation for railway vehicles," IFAC-Papers OnLine, vol. 50, no. 1, pp. 59615966, 2017.

[5] O. Cats, "The robustness value of public transport development plans," Journal of Transport Geography, vol. 51, pp. 236-246, 2016.

[6] W. Qu, F. Corman, and G. Lodewijks, "A review of real time railway traffic management during disturbances," in Proceedings of the International Conference on Computational Logistics, pp. 658-672, Springer, September 2015.

[7] H. Dong, B. Ning, Y. Chen et al., "Emergency management of urban rail transportation based on parallel systems," IEEE Transactions on Intelligent Transportation Systems, vol. 14, no. 2, pp. 627-636, 2013.

[8] W. Zhao, U. Martin, Y. Cui, and J. Liang, "Operational risk analysis of block sections in the railway network," Journal of Rail Transport Planning \& Management, 2017.

[9] M. D. Yap, N. Van Oort, R. Van Nes, and B. Van Arem, "Robustness of multi-level public transport networks: a methodology to quantify (un) robustness from a passenger perspective," Tijdschrift Vervoerswetenschap, vol. 51, no. 1, pp. 82-99, 2015.

[10] G. Cavone, M. Dotoli, N. Epicoco, and C. Seatzu, "Intermodal terminal planning by petri nets and data envelopment analysis," Control Engineering Practice, vol. 69, pp. 9-22, 2017.

[11] H. Zhang, Robust Cyclic Scheduling Applied to Container Management of Medium Sized Seaport [Doctoral Thesis], Ecole Centrale de Lille, 2014.

[12] W. Khansa, J. Denat, and S. PCollart-Dutilleul, "P-time petri nets for manufacturing systems," in Proceedings of the IEEE Workshop On Discrete Event Systems (WODES '96), pp. 94-102, August 1996.

[13] M. Gaied, D. Lefebvre, A. M'halla, and K. B. Othmen, "Modelling and Performance Evaluation of Railway transport Systems using P-timed Petri Nets," in Proceedings of the 5th International Conference on Control, Decision and Information Technologies (CoDIT '18), pp. 841-846, April 2018.

[14] S. Collart-Dutilleul, Commande Robuste D’Ateliers à Contraintes de Temps De Séjour: Application à la Galvanoplastie [Thèse De Doctorat], Université de Savoie, Annecy, France, 1997.

[15] J. Long, Sur la Conduite Hiérarchisée des Systèmes Flexibles de Production [Thèse de Doctorat], INPG Grenoble, 1993.

[16] A. Mhalla, S. C. Dutilleul, and H. Zhang, "Robust control under uncertainty for seaport handling equipments," Journal of Transportation Research Procedia, vol. 14, pp. 203-212, 2016.

[17] N. Jerbi, S. Collart Dutilleul, E. Craye, and M. Benrejeb, “Time disturbances and filtering of sensors signals in tolerant multiproduct job-shops with time constraints," International Journal of Computers, Communications \& Control, vol. I, no. 4, pp. 6172, 2006.

[18] A. Mhalla and M. Benrejeb, "Robust Control facing disturbances: Application to a coil winding machine," in Proceedings of the 5th Conférence Internationale en Automatique \& Traitement de Signal (ATS '17), March 2017.

[19] Y. I. Mahjoub, E. H. C. El-Alaoui, and A. Nait-Sidi-Moh, "Modeling a bus network for passengers transportation management using colored Petri nets and $(\max ,+)$ algebra," Procedia Computer Science, vol. 109, pp. 576-583, 2017. 
[20] H. Lü, W.-B. Shangguan, and D. Yu, "Uncertainty quantification of squeal instability under two fuzzy-interval cases," Fuzzy Sets and Systems, vol. 328, pp. 70-82, 2017.

[21] Y. Zhou, X. Tao, L. Luan, and Z. Wang, "Safety justification of train movement dynamic processes using evidence theory and reference models," Knowledge-Based Systems, vol. 139, pp. 7888, 2018. 


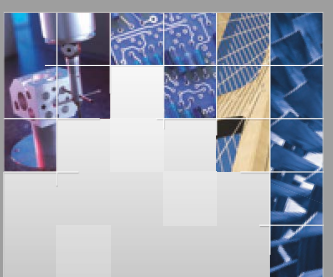

\section{Enfincering}
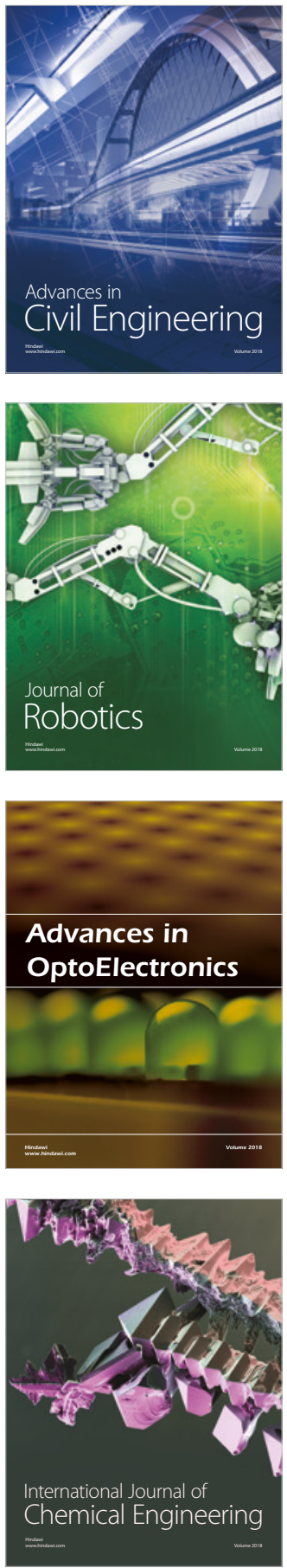

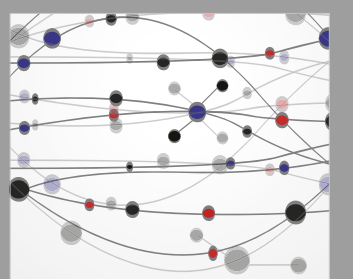

\section{Rotating \\ Machinery}

The Scientific World Journal

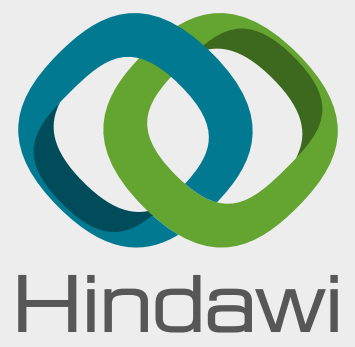

Submit your manuscripts at

www.hindawi.com
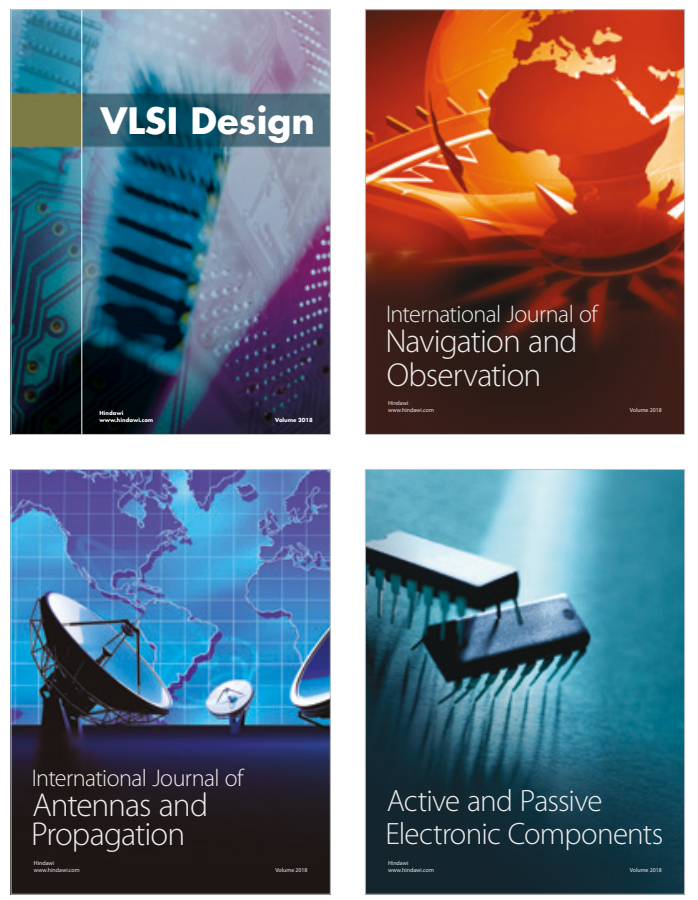
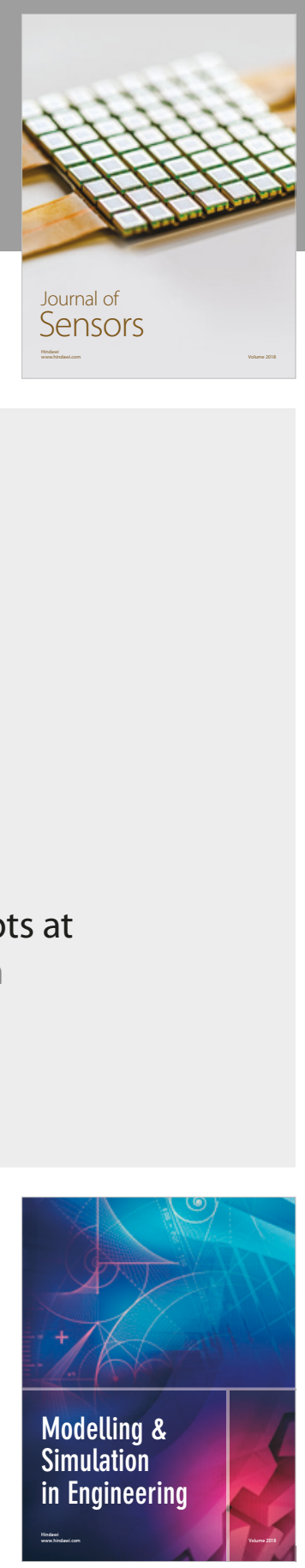

\section{Advances \\ Multimedia}
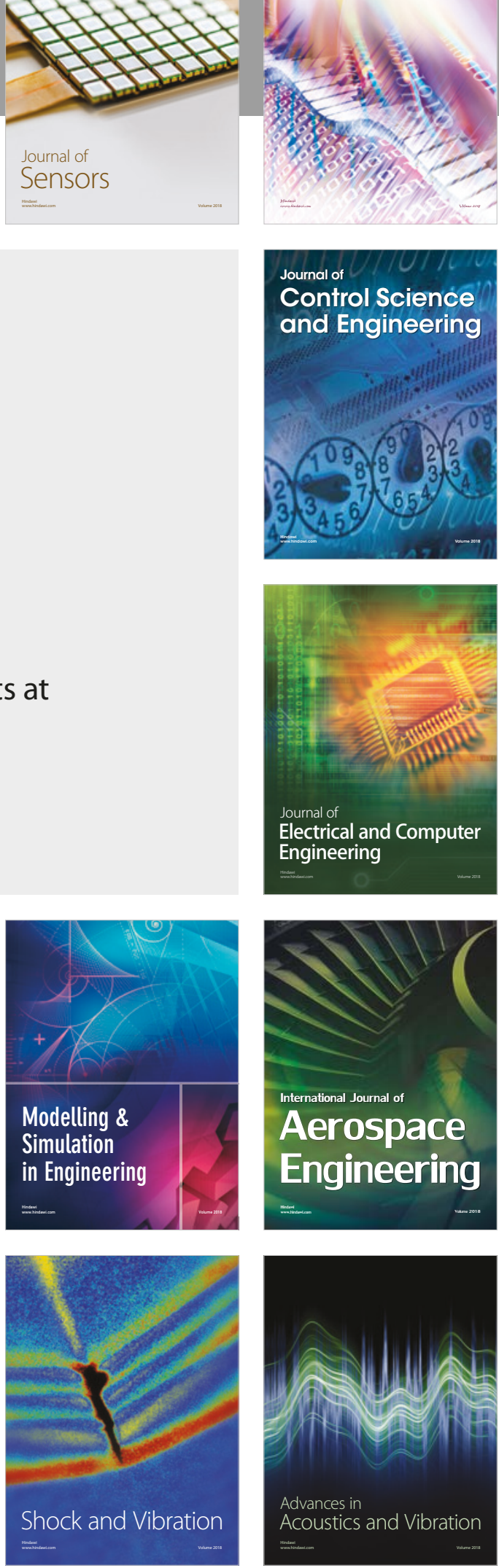